TITLE:

\title{
Measurement of mass flow rate of polymer powder based on static electrification of particles
}

\section{AUTHOR(S):}

Masuda, Hiroaki; Matsusaka, Shuji; Shimomura, Hiroaki

\section{CITATION:}

Masuda, Hiroaki ... [et al]. Measurement of mass flow rate of polymer powder based on static electrification of particles. Advanced Powder Technology 1998, 9(2): 169-179

\section{ISSUE DATE:}

1998

URL:

http://hdl.handle.net/2433/226657

\section{RIGHT:}

(C) 1998. This manuscript version is made available under the CC-BY-NC-ND 4.0 license http://creativecommons.org/licenses/by-nc-nd/4.0/; この論文は出版社版でありません。 引用の際には出版社版をご確認ご利用ください。; This is not the published version.

Please cite only the published version. 


\title{
Measurement of mass flow rate of polymer powder based on static electrification of particles
}

HIROAKI MASUDA, SHUJI MATSUSAKA and HIROAKI SHIMOMURA

Department of Chemical Engineering, Kyoto University, Yoshida-honmachi, Sakyo-ku, Kyoto 606-01, Japan

\begin{abstract}
Measurement of mass flow rate of polymer powder in a gas-solids pipe flow was investigated theoretically and experimentally. The measurement was based on the static electrification of the flowing particles. In the system, two current detecting pipes made of different materials were used and mass flow rates were calculated from the two generated currents. Since polymer powder formed a stiff coating layer on the hard surface of metallic pipes by particle collision, several polymer materials were examined as to the detecting pipes and the performance of the current detection was evaluated by changing the powder flow rate. It was found that electrically conductive polymers containing carbon had superior stability for the current detection. It was also found that the mass flow rate of polymer powder could be measured by use of two different conductive polymers for the detecting pipe
\end{abstract}




\section{NOMENCLATURE}

$a$

$b$

$I$

$m$

$n(x), n(\Delta x)$

$n^{\prime}$

$n_{0}$

$\left(q / m_{\mathrm{p}}\right)_{0}$

$\left(q / m_{\mathrm{p}}\right)_{\infty}$

$\bar{u}$

$X$

$\Delta \mathrm{x}$

$W_{\mathrm{p}}$

Greek

A

$\rho$

$\psi$ constant in Eq.(3) (-)

constant in Eq.(3) $\left(\mathrm{C} \mathrm{kg}^{-1}\right)$

electric current (A)

powder-to-air mass-flow ratio (-)

number of collisions of a particle (-)

number of collisions of a particle per unit pipe length $\left(\mathrm{m}^{-1}\right)$

relaxation number of collisions (-)

charge-to-mass ratio at $x=0\left(\mathrm{C} \mathrm{kg}^{-1}\right)$

charge-to-mass ratio at $\mathrm{x}=\infty\left(\mathrm{C} \mathrm{kg}^{-1}\right)$

average air velocity $\left(\mathrm{m} \mathrm{s}^{-1}\right)$

length from a point $(\mathrm{m})$

length of detecting pipe (m)

powder flow rate $\left(\mathrm{kg} \mathrm{s}^{-1}\right)$

ratio of space charge effect to image charge effect (-)

specific resistance $(\Omega \mathrm{m})$

relative humidity $(-)$ 


\section{INTRODUCTION}

In a gas-solids pipe flow, particles are charged as a result of particle collision with the pipe wall. On the basis of the static electrification, a method for measuring the powder flow rate was proposed [1]. The electrical method takes advantage of high sensitivity without obstructing the pipe flow. However, the method has fundamental problems the charge transfer between a particle and a wall depends both on the initial charge of the particle and on the electrostatic properties [2]. To resolve the problems, we proposed a new electrical method by analyzing the electric currents generated from two detecting pipes in series, which were made of different materials. From the experiments using mineral powders (fiy-ash and alumina), it was found that the dual-detecting system had high performance for the measurement of mass flow rate [3, 4].

Polymer powders as well as mineral powders are generally used in industry. Electrostatic powder coating [5], which receives attention for disuse of volatile organic compounds (VOC), will be taken as an example of the application of polymer pow- der. The powders, which are usually made from thermosetting resin, readily form a stiff coating layer on the wall surface in gas-solids pipe flow. This phenomenon is especially remarkable if a pipe wall is made of hard material like metal. There- fore, detecting pipes made of such materials like stainless steel, nickel, titanium nitride, etc., used for mineral powders $[3,4,6]$ cannot be used for polymer powders.

In this study, we use new detecting pipes made of various polymer materials to prevent the coating layer forming on the wall and conduct experiments to clarify the electrification of polymer powder in a pipe flow, and, moreover, evaluate the dual-detecting system for measuring the mass flow rate.

\section{THEORY}

When a pipe of a length of $\Delta x$ that is electrically isolated is grounded, the charge transferred from the particles to the pipe per unit time is measured as an electric current. Under conditions that the particle-particle interactions and particle-wall adhesion are negligible, the electric current per unit mass flow rate $I / W_{\mathrm{p}}$ is represented by the following equation [2]:

$$
\frac{I}{W_{\mathrm{p}}}=\left\{\left(\frac{q}{m_{\mathrm{p}}}\right)_{0}-\left(\frac{q}{m_{\mathrm{p}}}\right)_{\infty}\right\}\left\{e^{-n(x) / n_{0}}\right\}\left\{1-e^{-n(\Delta x) / n_{0}}\right\},
$$


where $\left(q / m_{\mathrm{p}}\right)_{0}$ and $\left(q / m_{\mathrm{p}}\right)_{\infty}$ are charge-to-mass ratio at $\mathrm{x}=0$ and $\mathrm{x}=\infty$, respectively, $n$ is the number of collisions of a particle, and no is the relaxation number. Equation (1) is a general equation, in which the length $x$ is not restricted. In the case of $x=0$ at the inlet of a current detecting pipe, the following equation is derived from equation (1):

$$
\frac{I}{W_{\mathrm{p}}}=\left\{\left(\frac{q}{m_{\mathrm{p}}}\right)_{0}-\left(\frac{q}{m_{\mathrm{p}}}\right)_{\infty}\right\}\left\{1-e^{-n(\Delta x) / n_{0}}\right\} .
$$

On the assumption that the charge transfer is due to the difference of the work function between contact bodies, the image charge effect, and the space charge effect, equation (2) can be rewritten as follows $[3,4,6]$

$$
\frac{I}{W_{\mathrm{p}}}=\left\{a(1+\alpha)\left(\frac{q}{m_{\mathrm{p}}}\right)_{0}+b\right\},
$$

where $a$ and $b$ are constants, a is the ratio of the space charge effect to the image charge effect. For $\alpha \ll 1$, equation (3) is simplified as follows:

$$
\frac{I}{W_{\mathrm{p}}}=a\left(\frac{q}{m_{\mathrm{p}}}\right)_{0}+b .
$$

When the two detecting pipes are set in series with electrical isolation, the following equations are obtained from equation (4) $[3,4]$ :

$$
\frac{I_{0}}{W_{\mathrm{p}}}=a_{0}\left(\frac{q}{m_{\mathrm{p}}}\right)_{0}+b_{0}
$$

and

$$
\frac{I_{1}}{W_{\mathrm{p}}}=a_{1}\left(\frac{q}{m_{\mathrm{p}}}\right)_{1}+b_{1} .
$$

Since the charge at the outlet of the first pipe should be equal to that at the inlet of the second, the following equation is obtained:

$$
\left(\frac{q}{m_{\mathrm{p}}}\right)_{0}-\left(\frac{q}{m_{\mathrm{p}}}\right)_{1}=\frac{I_{0}}{W_{\mathrm{p}}} .
$$

From equations (5)-(7), the powder flow rate $\mathrm{Wp}$ is given by the following equation:

$$
W_{\mathrm{p}}=\frac{a_{1}\left(a_{0}-1\right) I_{0}+a_{0} I_{1}}{a_{0} b_{1}-a_{1} b_{0}} .
$$

In equation (8), the denominator of the right-hand side must not be zero. Therefore, the characteristic value of the first detecting pipe -bo/ao must differ from that of the second $-b_{1} / a_{1}[3,4]$. 


\section{EXPERIMENTAL APPARATUS AND PROCEDURE}

Figure 1 shows the experimental apparatus. Test powder (epoxy resin for electrostatic powder coating; mass median diameter: $33 / \mathrm{tm}$; particle density: $1450 \mathrm{~kg} \mathrm{~m}^{-3}$ ) was fed by use of a table feeder (Sankyo Pio-tech, MFOV-1) to an ejector-type disperser (Nippon Pisco, VHL15-1002J). The pipe was $6 \mathrm{~mm}$ in inner diameter and the average air velocity was constant at $29 \mathrm{~m} \mathrm{~s}^{-1}$. Electric current detecting pipes, which were the test section of particle electrification, were set behind a fore-flow region of $400 \mathrm{~mm}$. The detecting pipes were made of three different polymer materials, i.e. polytetrafluoroetylene (pure PTFE; specific resistance: $\rho>10^{16} \Omega \mathrm{m}$ ), electrically conductive PTFE containing carbon filler $\left(\rho=8 \times 10^{2} \Omega \mathrm{m}\right)$ and electrically conductive nylon containing carbon filler $(\rho=5 \Omega \mathrm{m})$. The polymer materials were cut in the shape of a cylinder (ID: $6 \mathrm{~mm}$; OD: $18 \mathrm{~mm}$; length: $100 \mathrm{~mm}$ ) and the outer cylinder was tightly covered by metal (brass). Each detecting pipe was electrically isolated from other pipes using small joints made of pure PTFE; the distance between pipe edges was less than $1 \mathrm{~mm}$ in the joint and an electric shield was set around the detecting pipes to prevent electric noise in the field. The currents generated from a detecting pipe were measured with an electrometer (Advantest, TR8651) and the data were automatically sampled into a computer (10 data/s). In the experiments for evaluation of the effect of pipe length, we used a maximum of three detecting pipes made of the same material in series. Furthermore, in the experiments for measurement of the powder flow rate, we used a scanner controlled by the computer to measure the currents generated from two detecting pipes by use of the single electrometer. Actual average powder flow rate was measured by weighing directly the powder dis- charged from the table feeder for a given while and the charge-to-mass ratio $\left(q / m_{\mathrm{p}}\right)_{0}$ at the inlet of a detecting pipe was measured with a vacuum-type Faraday cage. All experiments were conducted at room conditions (temperature: 289-296 K; relative humidity: 44-64\%).

\section{RESULTS AND DISCUSSION}

\subsection{Stability of currents generated from a polymer detecting pipe}

Figure 2 shows the currents generated from three kinds of polymer detecting pipes as a function of time elapsed. Although all the average currents were negative, large positive pulse currents were randomly generated from the pure PTFE detecting pipe, as shown in Fig. 2a. Such reverse currents were not detected from conductive detecting pipes (see Fig. $2 b$ and $c$ ) or from the metallic detecting pipes $[3,4,6]$. When conductive nylon 
pipes were connected before and behind the pure PTFE detecting pipe, large negative pulse currents were generated from the conductive nylon pipes. An example of the typical currents generated from the first conductive nylon pipe is shown in Fig. 3. Furthermore, when all the currents generated from the three detecting pipes were measured at a time, large pulse currents disappeared, as shown in Fig. 4. As a result of these facts, the following feature was deduced; since pure PTFE has high specific resistance, charge transferred from particles is stored in the pipe wall, and when the electric potential exceeds a critical value, electric discharge occurs toward the connected pipes and large pulse currents are detected. Therefore, to obtain stable currents, one should select a conductive material that does not store electric charge in the body

\subsection{Characteristic line of particle electrification}

Figure 5 shows the relationship between current per unit mass flow rate $I / W_{\mathrm{p}}$ and charge-to-mass ratio $\left(q / m_{\mathrm{p}}\right)_{0}$ of the conductive nylon pipe and the conductive PTFE pipe. The solid line shows an experimental characteristic line of particle electrification and the broken line shows the standard deviation of the scattered data. The results of our previous experiments using mineral powders showed that the relationship between $I / W_{\mathrm{p}}$ and $\left(q / m_{\mathrm{p}}\right)_{0}$ was linear (see equation (4)) when particles were fully dispersed in air, and particle-particle interactions and particle-wall adhesion are negligible. The present results also show that the relationship is adaptable for polymer powder, i.e. the characteristic lines of the conductive nylon pipe and the conductive PTFE pipe are represented by the following equations, respectively:

Conductive nylon pipe

$$
\frac{I}{W_{\mathrm{p}}}=5.6 \times 10^{-3}\left(\frac{q}{m_{\mathrm{p}}}\right)_{0}-2.8 \times 10^{-6}
$$

Conductive PTFE pipe

$$
\frac{I}{W_{\mathrm{p}}}=0.21\left(\frac{q}{m_{\mathrm{p}}}\right)_{0}-2.1 \times 10^{-4} \text {. }
$$

In addition, the characteristic values $-b / a$ of the conductive nylon and the conductive PTFE pipe are $5.0 \times 10^{-4}$ and $1.0 \times 10^{-3}$ respectively.

4.3 Effect of pipe length on particle electrification 
Figure 6 shows the effect of pipe length on particle electrification by use of a maximum of three detecting pipes in series. As for the conductive nylon pipe, current per unit mass flow rate $1 / W_{\mathrm{p}}$ was proportional to pipe length Ax (see Fig. 6a), but in the conductive PTFE pipe, the increasing ratio of $I / W_{\mathrm{p}}$ decreases with increasing pipe length. This is because the value of $I / W_{\mathrm{p}}$ of the conductive PTFE pipe is much larger than that of the conductive nylon pipe, i.e. the cumulative charge in a particle is very large in the conductive PTFE pipe. Therefore, the amount of charge transferred will decrease due to the image charge effect. The phenomenon can be explained theoretically as follows. Since the number of particle collisions with an inner pipe wall will be proportional to the pipe length, when $\mathrm{n}^{\prime}$ is defined as the collision number per unit pipe length, equation (2) is rewritten as the following equation:

$$
\frac{I}{W_{\mathrm{p}}}=\left\{\left(\frac{q}{m_{\mathrm{p}}}\right)_{0}-\left(\frac{q}{m_{\mathrm{p}}}\right)_{\infty}\right\}\left\{1-e^{-n^{\prime} \Delta x / n_{0}}\right\},
$$

where is equal to the characteristic value $-b / a$ (see equations (2) and (4)). When the value of $-b / a$ obtained in Section 4.2 and the experimental value of $\left(q / m_{\mathrm{p}}\right)_{0}$ are substituted into equation (11), the theoretical lines are calculated (solid line and broken line in Fig. 6), where $n^{\prime} / n_{0}$ is a fitting parameter. Since $n^{\prime} / n_{0}$ corresponds to charging efficiency, the value for conductive PTFE would be larger than that for conductive nylon. Also, Fig. 6 shows that the experimental values agree well with the theoretical values regarding the effect of charge-to-mass ratio $\left(q / m_{\mathrm{p}}\right) 0$.

\subsection{Measurement of mass flow rate of polymer powder}

When the conductive nylon pipe and the conductive PTFE pipe were set in series, the powder flow rate corresponding to equation (8) is represented by the following equation:

$$
W_{\mathrm{p}}=3.6 \times 10^{5} I_{0}-9.5 \times 10^{3} I_{1}
$$

The comparison between the calculated powder flow rate and measured value is shown in Fig. 7. For reference, the scale of the powder-to-air mass flow ratio $\mathrm{m}$ is also shown on the right and upper sides. The calculated values agree with the measured values over a wide range; the relative error in the measurements was within $20 \%$. Thus, this system is applicable to on-line measurement of polymer powder as well as mineral powder by use of appropriate materials for the detecting pipes.

\section{CONCLUSION}


We have conducted experiments on the electrification of polymer powder and on the measurements of powder flow rate based on particle electrification and the following conclusions were drawn.

(1) Although large pulse currents are randomly generated from the polymer pipe wall, stable currents are only detected using conductive polymer materials containing carbon filler.

(2) When particle-particle interactions and particle-wall adhesion are negligible, the relationship between current per unit mass flow rate and charge-to-mass ratio is linear for polymer powder as well as mineral powder. The characteristic line of particle electrification depends on the wall materials.

(3) The effect of pipe length on particle electrification is explained by a theoretical equation based on the characteristic line of particle electrification and on the initial charge of particles.

(4) The dual-detecting system is applicable for the on-line measurement of the mass flow rate of polymer powder over a wide range by use of appropriate materials for the detecting pipes.

\section{Acknowledgements}

This research was supported by a Grant-in-Aid for Scientific Research no. 08455355 from the Ministry of Education, Science and Culture, Japan and also financially supported by Hosokawa Co., Ltd. The authors wish to express their appreciation.

\section{REFERENCES}

1. K. Iinoya, K. Gotoh and K. Higashitani (Eds). In: Powder Technology Handbook. Marcel Dekker, New York (1991), pp. 743-756.

2. H. Masuda, T. Komatsu and K. Iinoya. The static electrification of particles in gas-solids pipe flow. AICHE J. 22, 558-564 (1976).

3. H. Masuda, S. Matsusaka and S. Nagatani. Measurements of powder flow rate in gas-solids pipe flow based on the static electrification of particles. Advanced Powder Technol. 5, 241-254 (1994).

4. H. Masuda, S. Matsusaka and H. Fujimoto. On-line simultaneous measurement of powder flow rate and electric charge of particles in gas-solids pipe flow - effect of air velocity on accuracy of measurement. Kagaku Kogaku Ronbunshu 21, 573-580 (1995). 
5. J. F. Hughes. Electrostatic Powder Coating. Research Studies Press, London (1984).

6. H. Masuda, S. Matsusaka, S. Akiba and H. Shimomura. Electrification of fine particles in gas-solids pipe flow. J. Soc. Powder Technol., Japan 34, 91-96 (1997). 


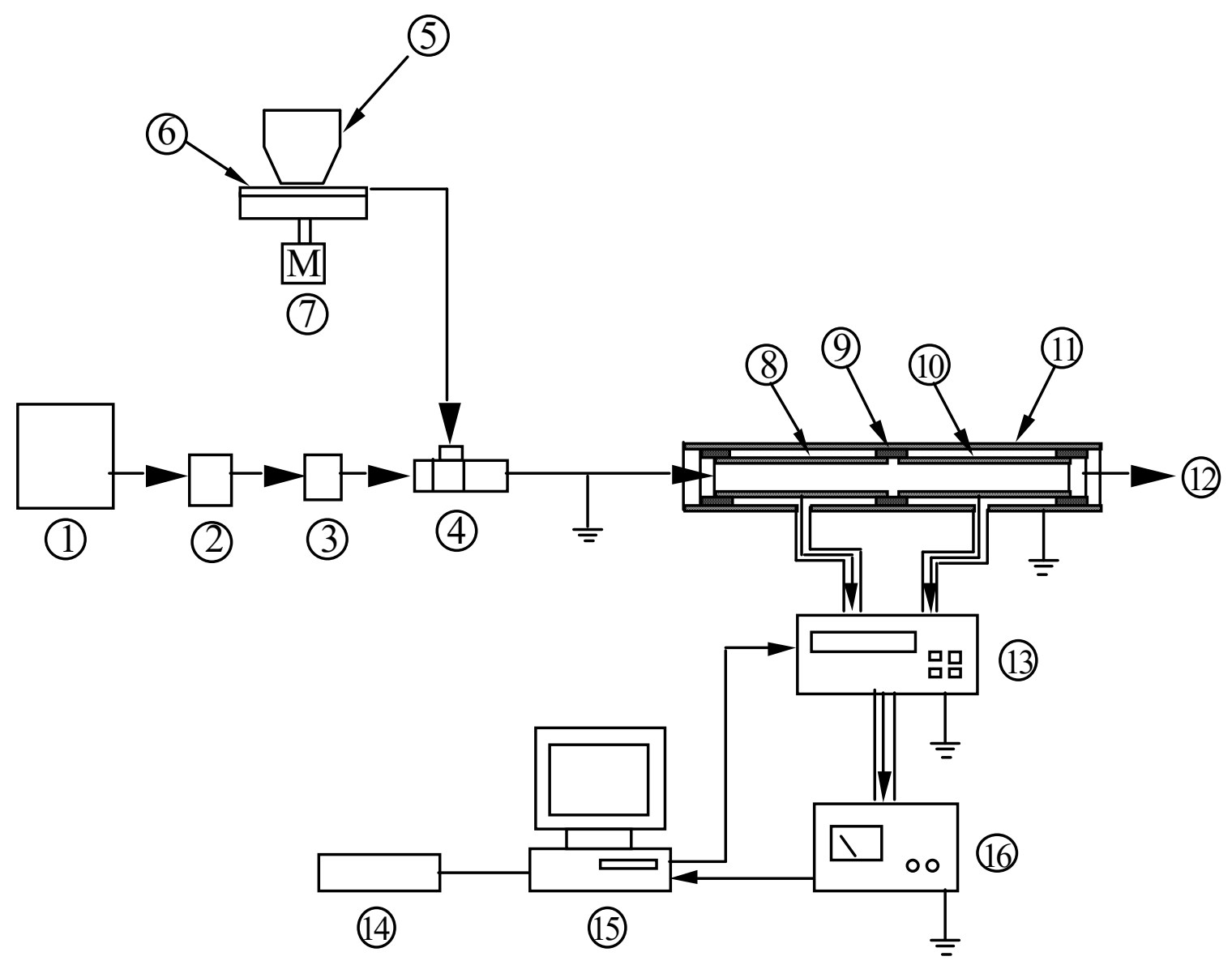
(1) Compressor
(9) Insulator
(2) Condenser
(10) Second detecting pipe
(3) Mist separator
(II) Electric shield
(4) Ejector
(12) Bag filter
(5) Hopper
(B) Scanner
(6) Powder layer
(14) Printer
(7) Table feeder
(15) Computer
(8) First detecting pipe
(16) Electrometer

Figure 1. Experimental apparatus. 

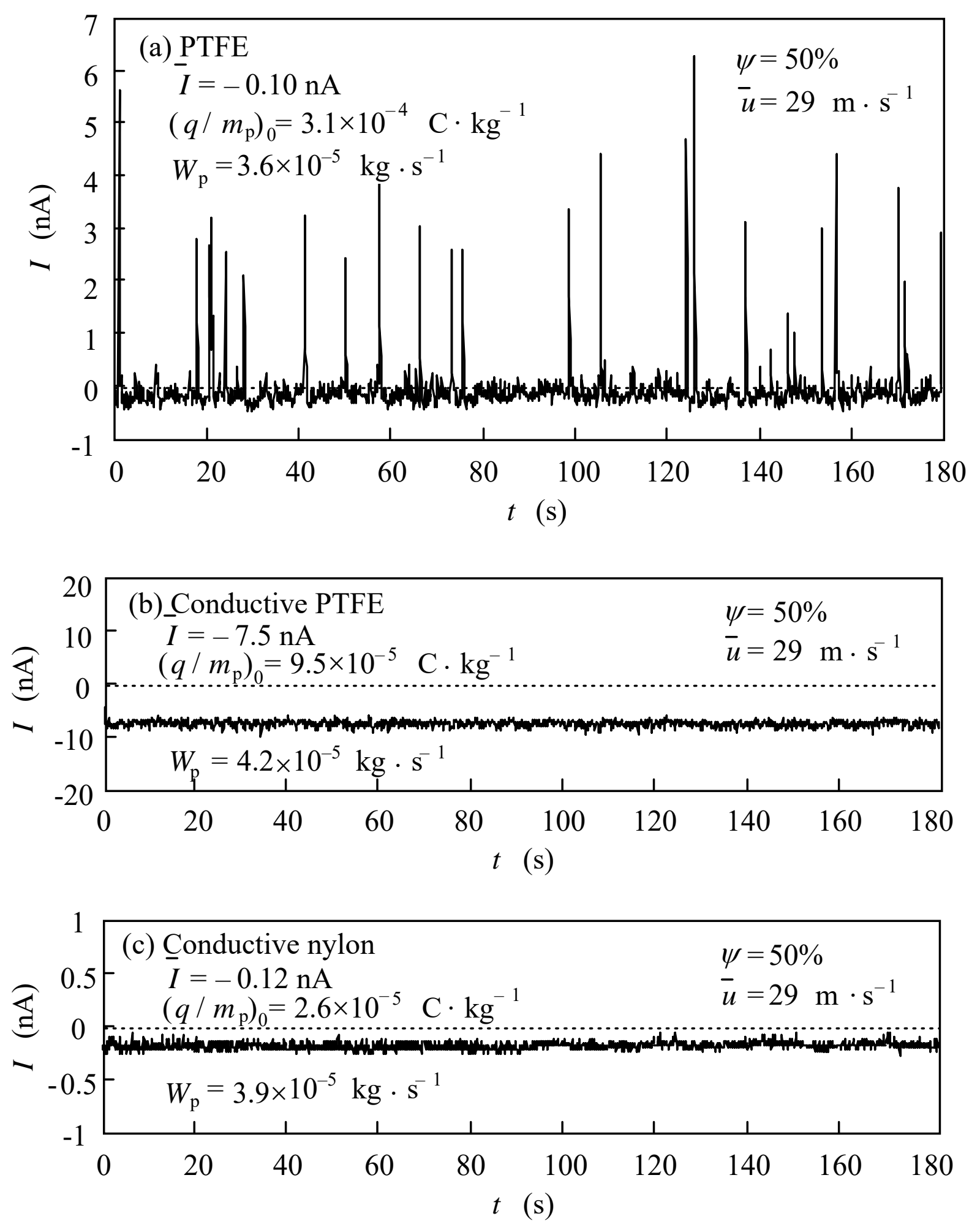

Figure 2. Currents $I$ generated from the detecting pipe. 


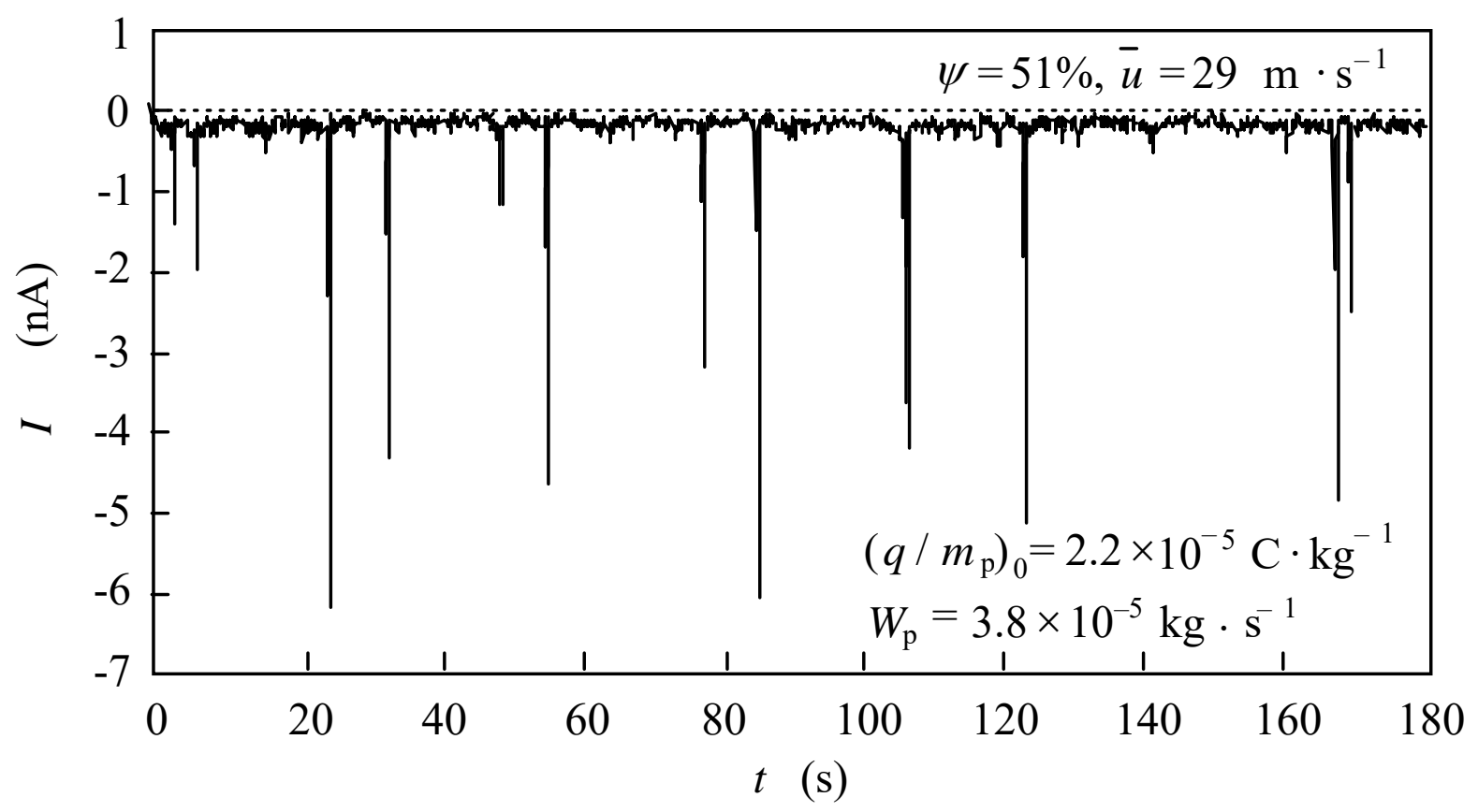

Figure 3. Currents I generated from the first conductive nylon pipe connected with the PTFE pipe. 


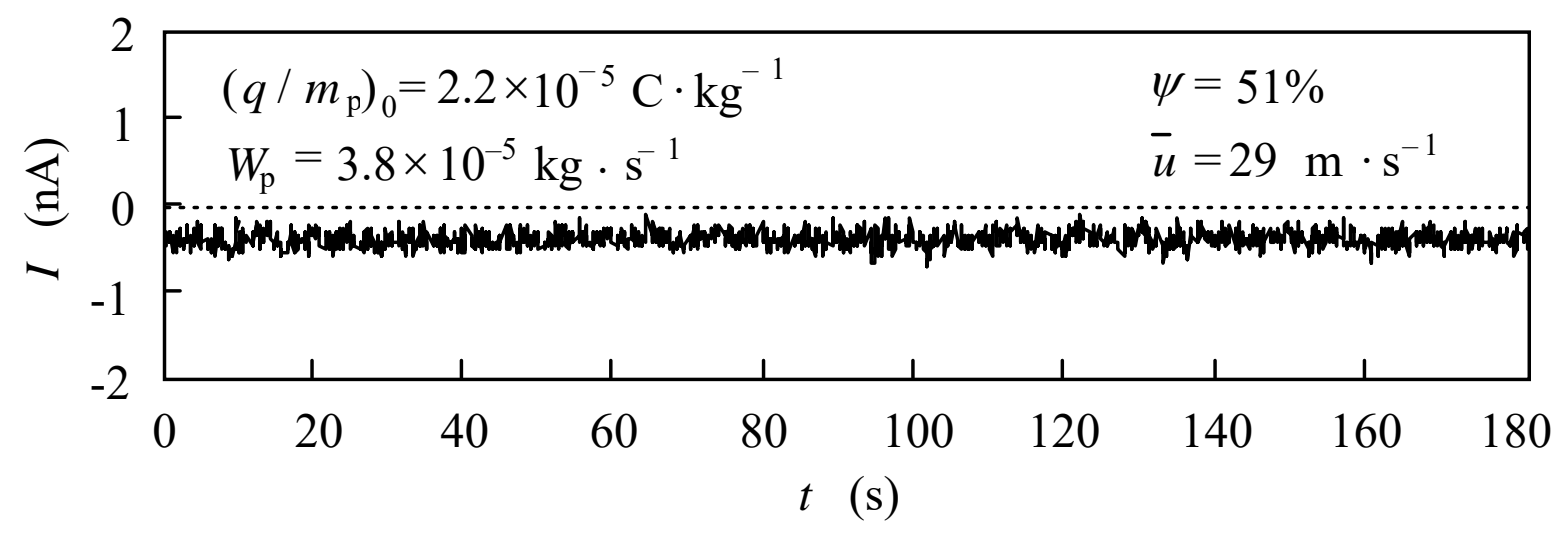

Figure 4. Total currents $I$ generated from a series of the three detecting pipes (PTFE pipe between conductive nylon pipes). 

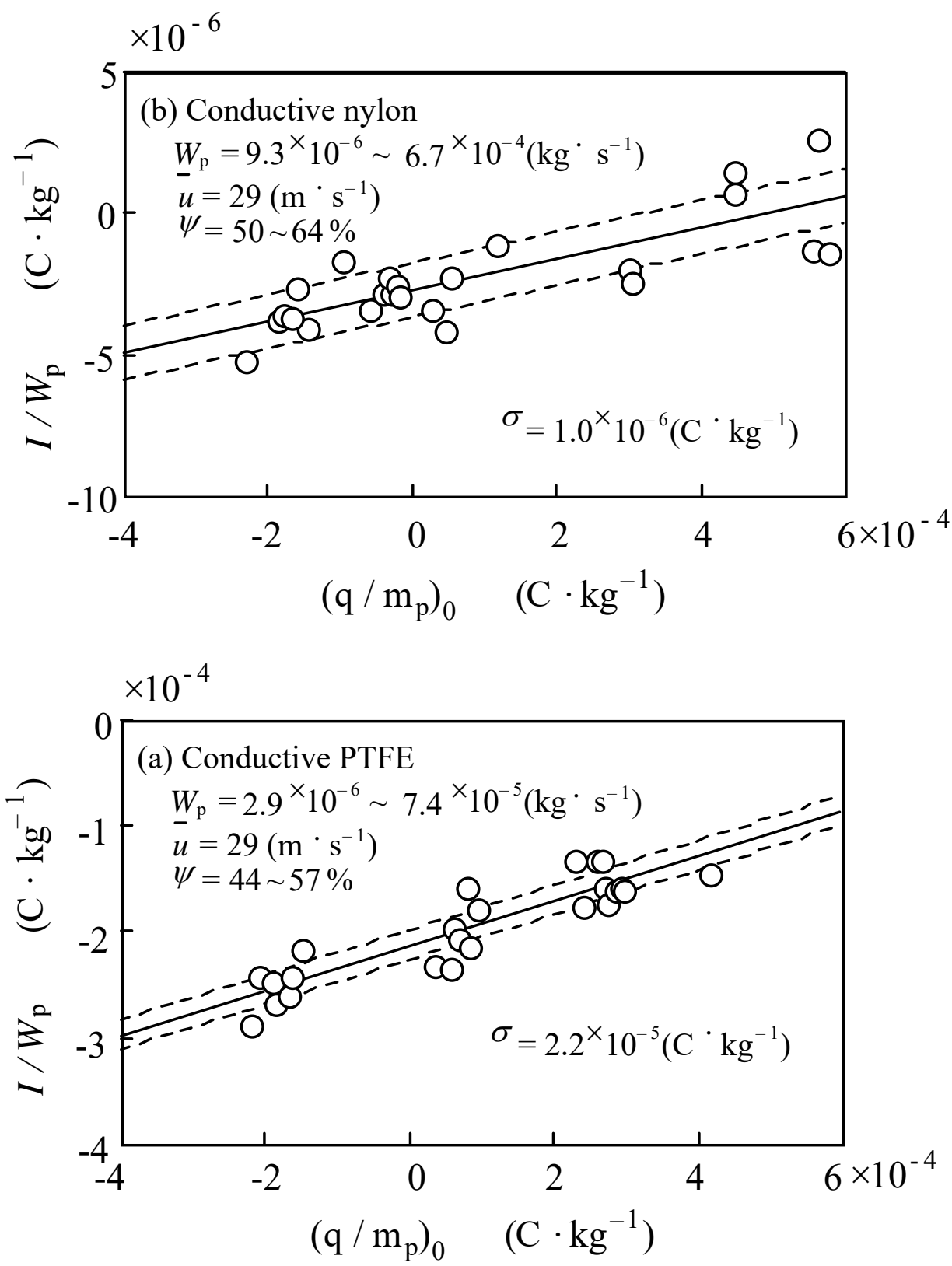

Figure 5. Characteristic line of electrification. 

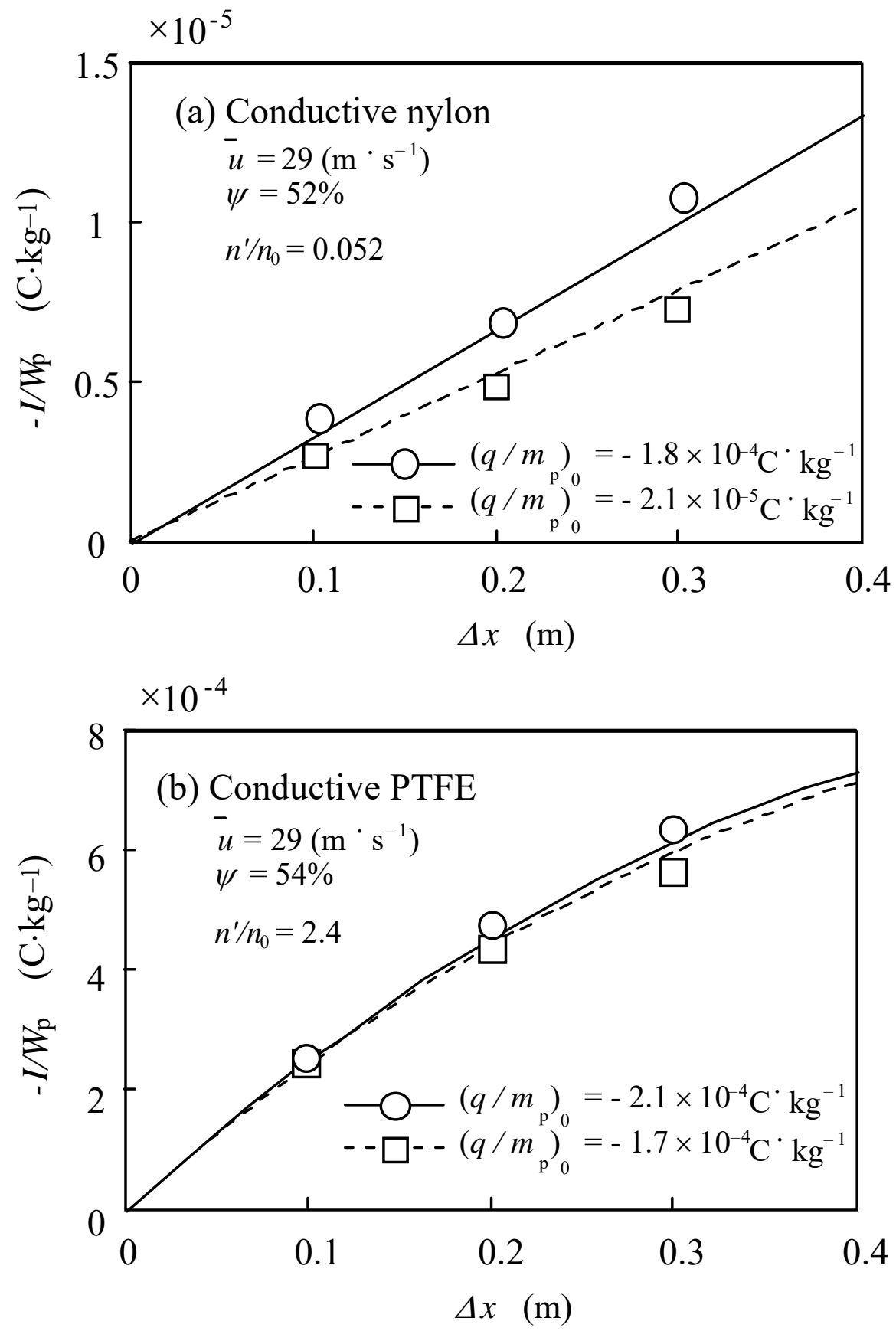

Figure 6. Effect of pipe length on electrification. 


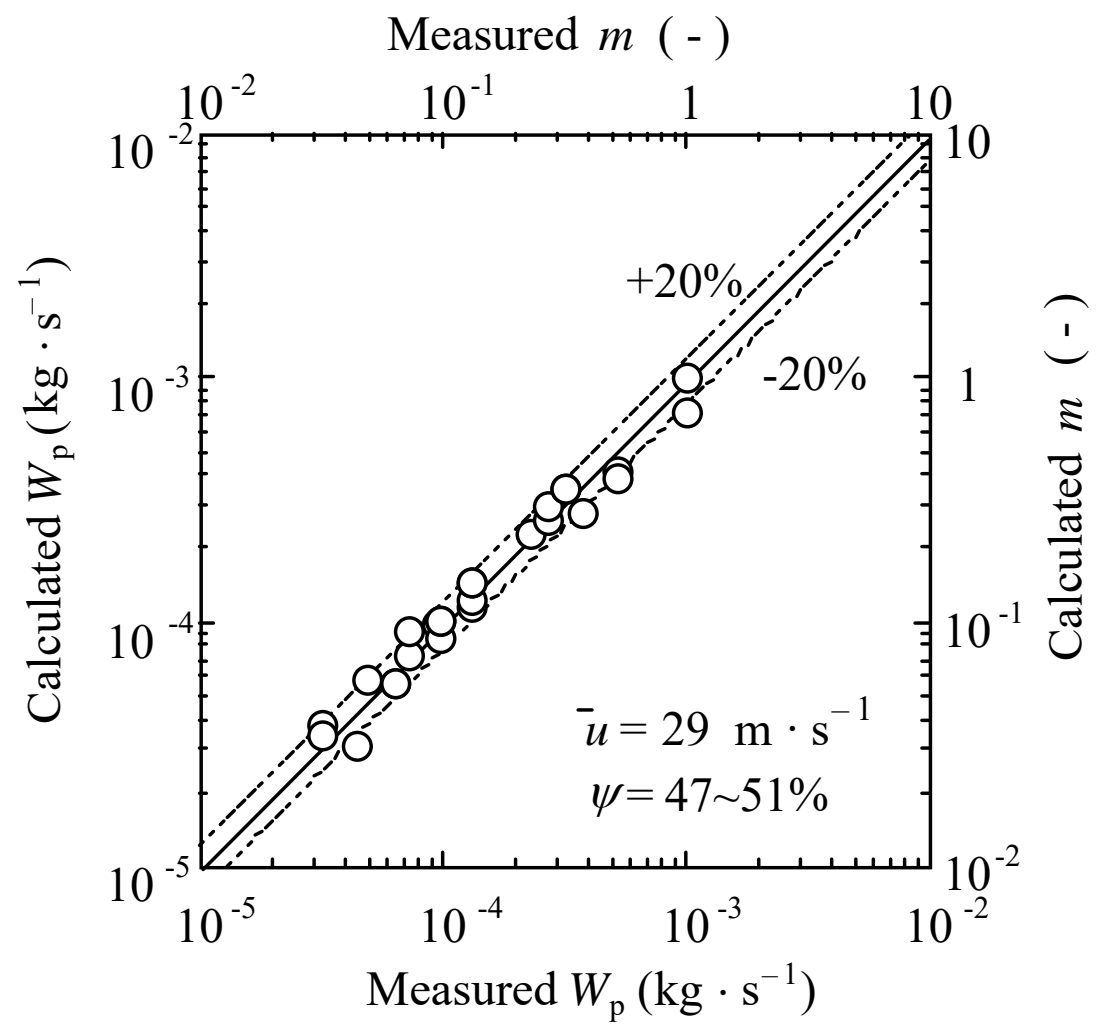

Figure 7. Comparison between calculated powder flow rate and measured value. 